\title{
CONDUTAS AUTOLESIVAS ENTRE DETENTAS DA COLÔNIA PENAL FEMININA DO RECIFE
}

\author{
Marcus Túlio Caldas \\ Renata Lopes Arcoverde \\ Thácio Ferreira dos Santos" \\ Mariana Spinelli Lima $^{\text {}}$ \\ Louise E. de Magalhães L. Macedo \\ Marcílio Cavalcanti Lima ${ }^{\Phi}$
}

\begin{abstract}
RESUMO. Esse estudo pretende analisar possíveis fatores de influência para condutas autolesivas entre detentas da Colônia Penal Feminina do Recife. Seus objetivos específicos incluem formular estratégias de intervenção que diminuam a incidência dessa prática. Dois questionários foram elaborados: o primeiro para realizar um censo com todas as detentas, determinando a extensão do comportamento autolesivo e selecionando a amostra; o segundo para aplicação nos sujeitos selecionados, detalhando esse comportamento. Para coleta de dados qualitativos utilizamos um diário de campo e entrevistas semidirigidas aplicadas coletivamente. Para análise dos dados usamos o método quantitativo de análise estatística descritiva e o método qualitativo de análise temática. Foram identificados vários fatores correlacionados à autolesão: alívio de sofrimento psíquico advindo do ambiente carcerário; raiva de si ou de outros; uso de drogas; tentativas de manipulação para obter vantagens no presídio e tentativas de comunicação e afirmação da individualidade num ambiente coletivo.
\end{abstract}

Palavras-chave: Autolesão, penitenciária, comportamento.

\section{SELF-HARM BEHAVIOR AMONG BRAZILIAN WOMEN IN RECIFE PRISON}

\begin{abstract}
This study intends to analyse possible influence factors on self-harm among incarcerated Brazilian women from the feminine criminal colony of Recife. Its specific objectives include formulating intervention strategies to reduce the incidence of those behaviors. Two questionnaires were elaborated: the first one to carry through a census with all prisoners and select the sample, determining the extension of self-harm; the second one is for specific application with selected prisoners, to go deeper in self-harm study. Qualitative data were collected through observation notes and half-directed interviews in groups. Data analysis included quantitative method of descriptive statistics analysis and qualitative method of thematic analysis. Several factors correlated to self-harm were found: relief of psychological suffering as a result from the incarceration environment; self-anger or anger of others; drug use; manipulative attempts to get advantages in the prison and attempts to communicate and affirmation of individuality in a collective environment.
\end{abstract}

Key words: Self-harm, prison, behavior.

\section{CONDUCTAS AUTO LESIVAS ENTRE DETENIDAS DE LA “COLONIA PENAL FEMENINA DE RECIFE"}

\footnotetext{
RESUMEN. Este estudo intenta analizar posibles factores de influencia para conductas auto lesivas entre detenidas de la "Colonia Penal Femenina de Recife". Sus objetivos específicos incluyen formular estrategias de intervenciones que disminuyan la incidencia de esta práctica. Dos cuestionarios fueran elaborados: el primero para realizar un censo con todas las detenidas, determinando la extensión del comportamiento auto lesivo y seleccionando la muestra; el otro para aplicación en los sujetos seleccionados, detallando este comportamiento. Para colecta de datos cualitativos utilizamos un diario de campo y entrevistas semidirigidas aplicadas colectivamente. Para análisis de los datos usamos el método cuantitativo de análisis estadístico descriptivo y el método cualitativo de

* Doutor em Psicologia. Professor adjunto I do Curso de Psicologia da Universidade Católica de Pernambuco-UNICAP.

\# Psicóloga da Universidade Federal de Pernambuco-UFPE.

II Psicólogo Clínico.

æ Psicóloga Clínica.

Æ Psicóloga da Prefeitura de Barreiros-PE e do Centro de Referência de Assistência Social Tamandaré-PE.

Ф Presidente da Associação de Usuários de Álcool e outras Drogas de Pernambuco-PE.
} 
análisis temático. Fueran identificados varios factores correlacionados con la autolesione: alivio del sufrimiento psíquico advenido del ambiente carcelario, rabia de si o del otro, uso de droga, intento de manipulación para tener ventaja en el presidio e intento de comunicación y afirmación de la individualidad en un ambiente colectivo.

Palabras-clave: Autolesión, penitenciaria, comportamiento..

Esta pesquisa teve como objetivos identificar e analisar possíveis fatores correlacionais ou de influência para condutas autolesivas entre as detentas da Colônia Penal Feminina da cidade do Recife, além de compreender a especificidade da autolesão na situação de privação de liberdade e formular estratégias de intervenção que diminuíssem a incidência de condutas autolesivas na penitenciária.

A conduta autolesiva é descrita como o ato de se machucar ou de fazer mal a si mesmo sem intenção de suicídio manifesta ou perversão sexual, através da provocação de danos físicos leves ou moderados (Kaplan, Sadock \& Grebb, 1997). Segundo os mesmos autores, os motivos mais comuns apresentados na literatura para esse comportamento são: raiva de si mesmo ou de outros, alívio de tensão, desvio do foco de atenção da dor emocional para a dor física e desejo inconsciente de morrer. Suyemoto (1998) diz que há uma ambivalência do sujeito quanto a seu desejo pela vida ou pela morte. Os ferimentos autoinduzidos teriam a intenção de aliviar sentimentos de culpa sacrificando uma parte do corpo mas permitindo a continuação da vida. Estudos da psiquiatria dinâmica apontam para maior frequência de condutas autolesivas entre pacientes com transtorno de personalidade borderline (Gabbard, 1992). Pessoas com este transtorno têm dificuldade de confiar nos outros, e isso se relaciona à convicção de que elas podem ser rejeitadas a qualquer momento. Assim, é comum que recorram a comportamentos autodestrutivos para provocar atitudes salvadoras.

Yaryura-Tobias, Mancebo e Neziroglu (1999) descrevem "efeitos contagiosos" em pacientes detidos para observação, indicando que o comportamento autolesivo, quando recompensado, faz com que outros pacientes o imitem para, provavelmente, também conseguir ganhos secundários. Se a atenção é a consequência desejada com a conduta, sendo ela conseguida, tanto reforçará o ato como poderá resultar em uma epidemia na instituição. Hales, Davison, Misch e Taylor (2003) relatam que esse mesmo mecanismo pode ocorrer em presídios, indicando que o encarceramento parece ser um fator de vulnerabilidade para a autolesão, na medida em que aumenta o risco de exposição a pessoas que se machucam propositalmente. Em sua pesquisa, os participantes associavam seu próprio comportamento autolesivo ao contato com essas pessoas.

Pierce (1984) descreveu o ato de se ferir como uma possível tentativa de comunicar um problema interpessoal: se o ato inicial é ignorado, ou ocorre uma resposta não solidária ou desagradável, então o comportamento autolesivo pode ser repetido de uma maneira mais ameaçadora até que seu objetivo seja alcançado. No cárcere, os métodos adotados para a autolesão variam de acordo com o ambiente. A restrição do porte de armas brancas ou de fogo, assim como de qualquer objeto cortante que possa servir de arma, influencia na escolha de outros métodos de autolesão (Power \& Spencer, 1987).

Também foram feitos levantamentos em prisões britânicas, que se mostraram preocupantes. O Safer Custody Group (2006), grupo de especialistas da polícia britânica que pesquisa as condições de vida nos presídios ingleses, apresentou um relatório que mostra os seguintes dados: 5.873 indivíduos se autolesionaram nas unidades prisionais da Inglaterra e País de Gales no ano de 2006, correspondendo a $7,5 \%$ da população prisional. $O$ relatório cita ainda que o número de incidentes de autolesão por mulheres se mostrou desproporcional à sua representação, uma vez que elas apresentaram 16 vezes mais ocorrências do que os homens prisioneiros, apesar de representarem apenas $6 \%$ do total da população prisional desses países em 2006.

\section{METODOLOGIA}

Amostra: Do total de 383 pessoas detidas quando se iniciou a pesquisa, 88 não participaram por motivos diversos: algumas se recusaram, outras estavam em horário de trabalho no momento da abordagem dos pesquisadores, e uma parcela estava na cela especial de detenção, que fica afastada do pavilhão de celaspadrão da penitenciária. Responderam ao primeiro questionário 295 apenadas, sendo 279 destes formulários válidos e 16 inválidos. 
As 279 detentas que responderam validamente ao questionário n. ${ }^{\circ} 1$ correspondem a 77,02\% da população prisional. Desta amostra, 48 pessoas apresentam ou já apresentaram condutas autolesivas e foram selecionadas para responder ao questionário $\mathrm{n}$. 2. Por fim, 19 pessoas responderam a este instrumento, correspondendo a $39,58 \%$ das que apresentam esse comportamento. A amostra final para o questionário n. ${ }^{\circ} 2$ não pôde alcançar todas as detentas que relataram já ter se machucado propositalmente por diversos fatores: quatorze pessoas saíram da prisão entre a aplicação de um questionário e a de outro; seis se recusaram a continuar na pesquisa; quatro passaram para o regime semiaberto, e em função disso estiveram fora do presídio durante a visita dos pesquisadores; uma permaneceu na cela de isolamento e outras quatro não o responderam por motivos diversos.

\section{Instrumentos}

Foram elaborados dois questionários: o primeiro para realizar um censo com todas as detentas, determinando a extensão do comportamento autolesivo e selecionando a amostra, com dados de identificação e perguntas sobre a ocorrência ou não de autolesão; o segundo, para aplicação nos sujeitos selecionados, detalhando esse comportamento com perguntas sobre os motivos da autolesão, influência do uso de drogas no comportamento autolesivo, presença de dor ao se machucar e sugestões para diminuição da ocorrência desse comportamento. Também foram realizadas entrevistas semidirigidas em grupo com as apenadas, com a intenção de compreender as emoções e experiências relacionadas à questão. As entrevistas foram realizadas no pátio da penitenciária, com a presença dos pesquisadores, sem interferência dos funcionários, com a participação de 16 detentas. $\mathrm{O}$ roteiro dessa entrevista continha questões sobre o sentimento das detentas com relação a outras pessoas que se machucam de propósito no presídio, o sentimento com relação a si próprias após autolesão, e os tipos de vantagens (ganhos secundários) obtidos por elas ao se ferirem propositalmente no presídio. Utilizamos ainda um diário de campo, no qual fizemos as anotações dos dados mais importantes do dia-a-dia da pesquisa. Estes dois últimos instrumentos serviram para o registro dos dados qualitativos.

\section{Procedimento de análise dos dados}

Utilizou-se o método qualitativo de análise temática proposto por Severino (2007) para avaliar as entrevistas semidirigidas realizadas em grupo e as observações feitas no diário de campo. O método quantitativo de análise estatística descritiva foi usado para a análise dos questionários $n .^{\circ} 1 \mathrm{e} \mathrm{n} .^{\circ} 2$. Os dados coletados nesses questionários foram relacionados, na fase de discussão dos resultados, com os dados qualitativos apresentados nos outros instrumentos.

\section{RESULTADOS}

O número de detentas é decrescente em relação à idade, com $81,4 \%$ delas entre 18 e 39 anos. Grande parte das detentas que estão presas há menos de um ano é sumariada, representando $48 \%$ do total. Apenas $5 \%$ das detentas cumprem regime semiaberto, portanto 95\% delas estão em regime fechado (se incluirmos as sumariadas, que aguardam julgamento detidas). A porcentagem de presas que apresentaram condutas autolesivas em nossa amostra se aproxima de 17\%, incidência similar à de outras instituições de restrição ou privação da liberdade. Estudo feito na Grécia indicou que $15 \%$ de 80 detentos escolhidos numa amostra aleatória, feita numa prisão masculina grega, apresentavam ou já haviam apresentado condutas autolesivas em algum momento de sua vida (Fotiadou, Livaditis, Manou, Kaniotou \& Xenitidis, 2006).

Acreditamos que episódios de autolesão são maiores em situação de restrição de liberdade do que na população geral. Há dados de alguns autores americanos que relatam a média de $4 \%$ de incidência de autolesão em populações não-clínicas (Klonsky, Oltmanns \& Turkheimer, 2003), enquanto em prisões da Inglaterra e País de Gales (situações de privação da liberdade) há estudos que mostram incidência de $10 \%$ deste tipo de conduta entre mulheres prisioneiras (O'Brien, Mortimer, Singleton \& Meltzer, 2001). Ainda nestes dois últimos países, outro estudo mostra que $31 \%$ de todas as mulheres mantidas sob custódia em 2006 se machucaram propositalmente (Safer Custody Group, 2006).

Muitas participantes $(47 \%)$ já haviam expressado comportamento autodestrutivo na forma de lesões voluntárias ao próprio corpo antes de seu ingresso na prisão, conforme demonstrado na Figura 1, abaixo; porém a porcentagem de $53 \%$ de pessoas que passaram a apresentar esse tipo de conduta, após ser presa, é alta e podemos entender que o ambiente da instituição é um fator que influencia essa prática. A maioria das mulheres $(67 \%)$ diz ter se machucado entre uma e três vezes após sua prisão. Em segundo lugar, 22\% afirmam que se machucaram 12 vezes ou mais e, por fim, $11 \%$ não souberam responder ou não se lembravam do número de ocorrências. 


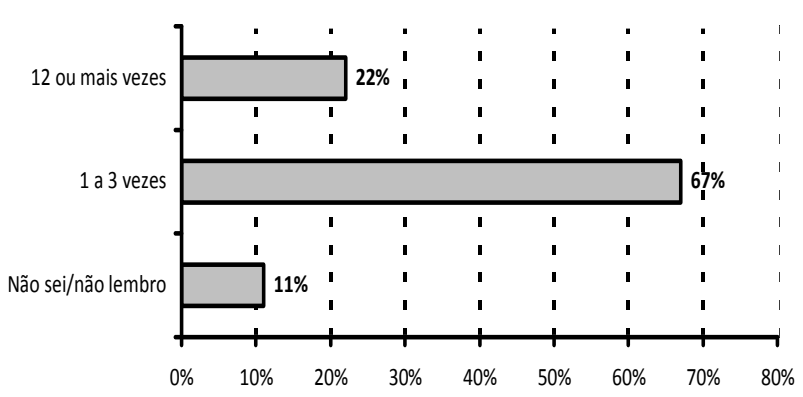

Figura 1. Número de Incidências de Autolesão Após Detenção

Do total de participantes, $79 \%$ disseram ter se machucado por estar com raiva (de si ou de outros); $74 \%$ relataram que o fizeram para aliviar a dor ou sofrimento; e $74 \%$ para não machucar outras pessoas. Aquelas que afirmam se machucar para obter vantagens compõem $58 \%$ da amostra. Entre essas vantagens, foram citadas nas entrevistas coletivas: ter acesso a local externo ao presídio (através de socorro na ambulância até o hospital mais próximo); a própria atenção diferenciada que se recebe da equipe de saúde; ser levada para a cela restrita, com interesses diversos, como encontrar-se com alguém que esteja lá; ou sair do pavilhão de celas-padrão para fugir de alguém a quem se deve dinheiro. Embora as pessoas acreditem que há relação entre drogas e autolesão (68\%), elas não se veem como pessoas que se machucaram por estarem sob efeito de drogas, já que somente 37\% relacionam sua própria conduta ao uso dessas substâncias. Por fim, 37\% admitiram ter se machucado pensando em morrer e o mesmo percentual disse que tinha como motivo chamar a atenção. Estes dados estão sintetizados na Figura 2, abaixo:

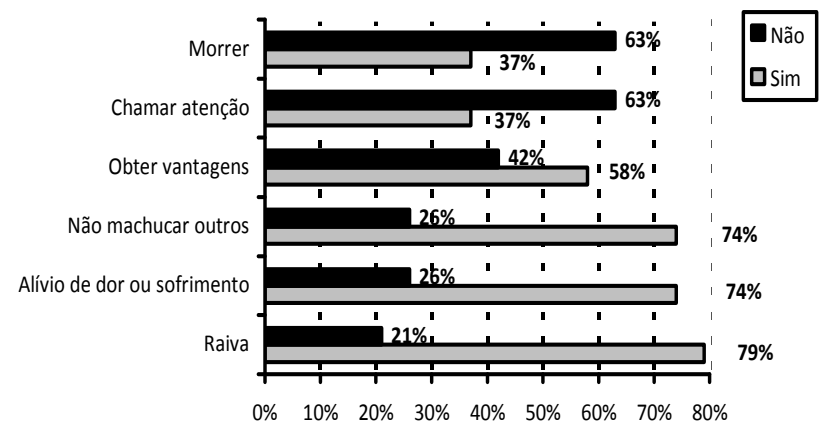

Figura 2. Motivos Alegados Para Prática Autolesiva

Os sentimentos relatados com relação a outras apenadas que se machucam mostram a aceitação social do fenômeno de autolesão (Figura 3): a maior frequência foi de sentimentos de solidariedade e mobilização, com $42 \%$ relatando vontade de ajudar essas pessoas, e $32 \%$ com sentimentos de tristeza ou pena, somando $74 \%$ no total. Provavelmente, essas pessoas também gostariam de ser ajudadas quando se machucam. Isso demonstra que a autolesão surte um efeito de comunicação - essa conduta não é considerada pelas apenadas como algo patológico ou que cause repulsa em larga escala, pois $21 \%$ são indiferentes (disseram não sentir nada) e 5\% sentem raiva das pessoas que se machucam propositalmente.

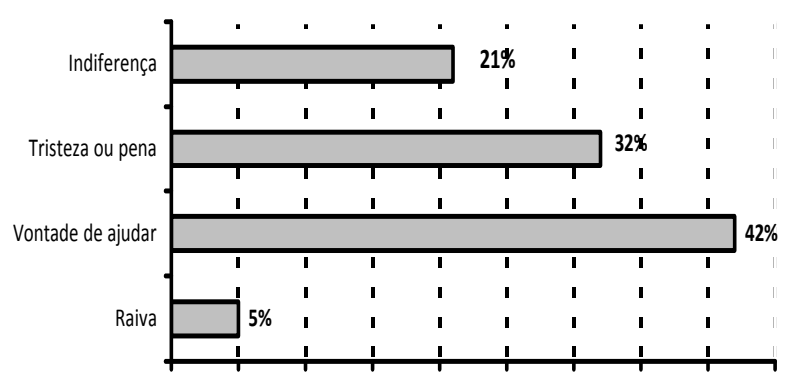

Figura 3. Sentimento com Relação a Outras Pessoas que se Autolesionam

Como sugestões das detentas para intervenções que poderiam diminuir o número de ocorrências de autolesão (Figura 4), foram citadas: atendimento psicológico, com 37,9\%; diminuição do uso de drogas, com $17,2 \%$; ter orientação religiosa; receber mais atenção dos funcionários; ser solta, com 10,3\% cada; e ter mais contato com a família, com percentual de $7 \%$. Outras 7\% afirmaram acreditar que nada poderia diminuir os casos de autolesão na penitenciária.

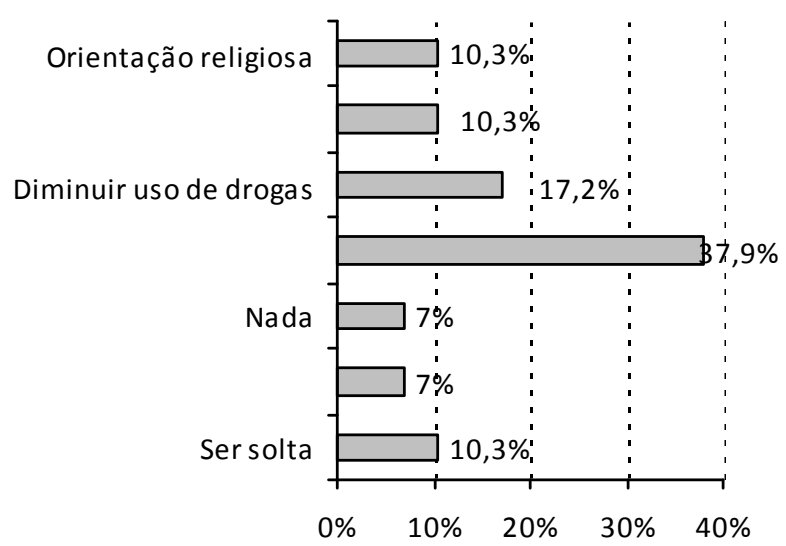

Figura 4. Sugestões das Detentas para Diminuição de Incidências de Autolesão no Presídio

\section{DISCUSSÃO}

Nas entrevistas em grupo não observamos um caráter compulsivo no ato de machucar-se da maioria da amostra, mesmo entre aquelas que o fizeram mais de 12 vezes (22\%). Constatamos que, das apenadas que não se lembravam de quantas vezes haviam se 
cortado, apenas uma sugeria um comportamento compulsivo. Esta mulher já se machucava antes mesmo de sua entrada na prisão e seus braços já se mostravam deformados por conta das diversas autolesões. Este pode ser um caso específico de comportamento autolesivo patológico dentro da penitenciária, porém não corresponde à realidade apresentada pela maioria da população estudada. Há um leque de motivos na conduta autolesiva das mulheres, que termina por se tornar uma forma de comunicação dentro do presídio. Algumas mulheres ilustram esses motivos (os nomes são fictícios):

Tem vez que é pra passear de ambulância, ou pra ir pro Japão (cela do castigo), pra pegar a massa (maconha) ou a pedra (crack), ou 'roupinol' ou qualquer coisa. E tem vez que é porque aqui dentro é muito ruim. A pessoa fica sem fazer nada, essa cadeia (...) dá vontade mesmo de se cortar (Olga).

Eu acho que tem de muito jeito diferente, que cada um é cada um. Mas aqui na prisão é mais ou menos tudo parecido. Eu só vejo o povo dizendo que vai se cortar, que vai fazer isso, vai fazer aquilo. Agora, tem umas que já se cortavam. Aí essas pode ser que tenha lá seus motivos, mas aqui dentro é tudo igual mesmo, pra mim é tudo igual. É coisa de droga, de querer se mostrar, ou então diz que quer ver a rua, vai pro hospital e diz que é pra ver a rua lá fora (Joana).

Segundo Rocha (2006), a comunicação pode acontecer verbalmente e/ou por meio de ações. Quando a expressão verbal é impedida de alguma forma (no caso de ambientes repressores - como um presídio, por exemplo), acontece a expressão comunicativa das emoções por meio de atos. Como vimos, $79 \%$ das apenadas afirmam já ter se machucado por estar com muita raiva, o que nos leva a crer que essas são características que apontam para um aspecto comunicativo da ação autolesiva na Colônia Penal. O comportamento autolesivo, portanto, pode ter um caráter metafórico. Pela falta de acolhimento do ambiente, a dor e a raiva são expressas através de uma ação - o ato de se machucar. Aqui a dor e o sofrimento são compreendidos num sentido amplo. Vão desde problemas pessoais e interpessoais até a relação com a instituição prisional. A grande abrangência de pessoas que citaram esse motivo (alívio da dor ou sofrimento) mostra a complexidade desse comportamento, que se revela muito mais abrangente do que um comportamento simplesmente patológico. É alternativa para a quebra da rotina e do tédio - o dia na prisão é longo, penoso.

Lembramos que há nas respostas das presas uma evidente percepção da relação entre os comportamentos de autolesão e uso de drogas, mas essa relação não é de causa e efeito, visto que as duas condutas têm um mesmo objetivo neste caso: a autolesão se compara à droga como fator de alívio da dor, do sofrimento no dia-a-dia dentro de um ambiente hostil, sendo alternativa para a quebra da rotina e do tédio. Provavelmente quem se machuca também usa drogas. A autolesão aqui se compara à droga como fator de alívio do sofrimento, no dia-a-dia em um ambiente hostil.

No contexto dessa pesquisa, as condutas autolesivas, mais do que uma forma de comunicação, são até uma moral: pensa-se no outro antes de se executar determinada ação. Vê-se, assim, como a presença da instituição determina a seleção de comportamentos. Esse nível de moralidade é estabelecido de forma imposta, pois $74 \%$ das apenadas afirmaram que não machucam o outro porque temem represálias, e então machucam a si mesmas. Uma delas afirma: "Não pode bater que senão apanha muito mais depois. Aí tem vez que a raiva é tanta, mas tanta, que a gente faz logo é na gente mesmo, bate logo na gente mesmo pra não ter que bater nos outros" (Clara). Esse tipo de conduta também foi mencionado por Assis e Constantino (2001, p. 251), que falam sobre um estudo em que as mulheres participantes "mostraram ser mais fácil utilizar estratégias em que a raiva se dirigisse para elas mesmas, resultando em comportamentos de autoflagelação (...)".

Apesar de apenas 37\% terem informado pretender chamar a atenção com o comportamento autolesivo, os pesquisadores identificam uma relação desse comportamento com a questão individualidadecoletividade. A busca por individualidade diante da coletividade também se expressa pelo ato autolesivo, que se configura, entre outras coisas, num ato para conseguir atenção para si, seja por meio da mobilização da equipe de saúde e agentes penitenciários, além do grupo de companheiras de cela, seja por meio da função de comunicação individual que expressa. É possível que as respostas dadas pelas mulheres tenham sido influenciadas pela associação entre chamar a atenção e se colocar no lugar de vítima, já que, no senso comum, apenas pessoas frágeis (de acordo com as próprias detentas) gostam de "chamar a atenção". Segundo uma delas: "Que chamar atenção o quê? Eu me corto na moral! 
Se esses guardinhas aí vierem com comédia eu me corto mesmo!' (Marta).

Como se vê, para algumas, o ato de se cortar é visto como uma atitude de bravura e de afronta à autoridade, uma vez que este comportamento é punido com a transferência da detenta para uma cela restrita, onde cabem até 10 mulheres. Assim, elas preferem não se colocar como vítimas, e sim como contestadoras da autoridade dos agentes penitenciários e seguranças ou como pessoas fortes e bem-decididas, que se ferem cientes das consequências de seus atos. Flemming, McDonald e Biles (1992) relatam estudos que explicam o fenômeno da autolesão sob custódia como atos que ocorrem em populações que são cronicamente entediadas, caso das pessoas encarceradas. Elas se machucariam para tentar provocar uma reação em outros ou fazer chantagem emocional e manipular as autoridades ligadas ao sistema prisional.

Analisando-se as respostas de pessoas que afirmaram já ter se machucado pensando em morrer (37\%), verifica-se que essa morte seria uma possível saída para uma situação insuportável relacionada ao fator depressor que o próprio ambiente prisional traz. Esse motivo não está ligado necessariamente ao suicídio, mas é uma morte simbólica: apesar de pensar em morrer, não há construção, através de condutas autolesivas, de um ato suicida. Além disso, a autolesão também é uma resposta a emoções pessoais, há uma preparação prévia ao ato, com a escolha de um objeto particular para se ferir, a escolha de uma parte do corpo específica, e até mesmo o anúncio de que haverá um ato autolesivo. Segundo relato das detentas, geralmente os antebraços são escolhidos como parte do corpo que será alvo de ferimentos.

O fenômeno de autolesão nessa população é frequente, socialmente aceito e não é feito às escondidas. Os machucados são expostos e até exibidos socialmente, sem grandes inibições, gerando comentários despreocupados entre essas mulheres, daí que $100 \%$ da amostra conhecem alguém que já se machucou propositalmente no presídio. Pudemos notar o desprendimento com que as participantes falavam sobre a autolesão, com pouca ou nenhuma vergonha de expressarem suas opiniões sobre o tema. Algumas chegavam a mostrar suas cicatrizes e contar as histórias por trás de cada uma delas, em narrativas semelhantes àquelas que se utilizam para contar fatos corriqueiros. Existe uma alta frequência de imitação, por parte de presas recém-chegadas, do comportamento autolesivo observado por elas em presas mais antigas, principalmente quando vantagens são conseguidas, corroborando os resultados encontrados em pesquisas anteriores (Hales, Davison, Misch \& Taylor, 2003).

Além disso, o alívio da dor emocional parece se sobrepor à dor física. É importante notar que, como $68 \%$ relataram não sentir dor, não se trata da manifestação de um comportamento masoquista. A dor física não parece ser elemento fundamental na conduta autolesiva dessa amostra. No caso dos $32 \%$ de presas que relataram sentir dor ao menos às vezes, podemos citar o mecanismo exposto por Richardson e Zaleski (1986): alguns indivíduos se tornariam dependentes de seu próprio sistema de opioides endógenos e recorreriam a ferimentos autoinduzidos para produzir maiores níveis de $\beta$-endorfina. Esse mecanismo poderia induzir a uma dependência da dor (na verdade, da $\beta$-endorfina) e ao curso crônico do comportamento autolesivo. Como dissemos, porém, não identificamos esse tipo de caráter compulsivo na maioria das mulheres.

Por fim, perguntamos acerca do que poderia diminuir a autolesão no presídio. Podemos entender a ideia do atendimento psicológico como espaço para acolhimento, expressão da individualidade em meio à coletividade e como uma das poucas possibilidades de expressão num ambiente de encarceramento. Como esses foram os motivos mais citados, é compreensível que a taxa de respostas para esse item seja a mais alta. Como vimos, o uso de drogas e as condutas autolesivas se apresentam como comportamentos paralelos, com a mesma função. Acreditamos que os $17,2 \%$ de detentas que marcaram o item diminuir $o$ uso de drogas percebem essa correlação. Receber atenção dos funcionários também foi um fator marcado com frequência $(10,3 \%)$. Mais uma vez, relacionamos este item com o caráter comunicativo do comportamento autolesivo na penitenciária. Presídios, em geral, são locais de pouco acolhimento às necessidades individuais de sua população, e isto não é diferente na Colônia Penal Feminina do Recife. A partir disso, nota-se certo ressentimento das detentas em relação ao tratamento dado pelos funcionários (nas entrevistas coletivas citou-se indiferença deles) a anseios, reivindicações e reclamações das apenadas. A conduta autolesiva torna-se então um veículo para comunicar insatisfação.

A opção ser solta foi citada em 10,3\% das vezes. Este dado relaciona-se à importante influência do ambiente carcerário no comportamento das detentas. Chama a atenção o dado de $7 \%$ das participantes que responderam ter mais contato com a família. $\mathrm{O}$ abandono dessas mulheres pela família após serem presas é algo frequente. Há poucas visitas de familiares às detentas. Lemgruber (1999) identifica 
isso como mais uma privação sofrida pelas prisioneiras e afirma que as mulheres sofrem maior abandono do que os homens prisioneiros. De fato, a Colônia Penal Feminina do Recife recebe um número proporcionalmente menor de visitas, se comparada a presídios masculinos da cidade. Quanto à atenção dos funcionários, em outra instituição prisional feminina, uma das detentas disse o seguinte: "Eu tava chamando e ele não tava querendo me atender. Não queria me ouvir. Eu chamava a diretora e ninguém queria me ouvir (...) Aí eu falei: 'Eu nunca me cortei, mas vou começar a me cortar.' Aí eu me cortei." (Assis \& Constantino, 2001, p. 252).

$\mathrm{O}$ item receber orientação religiosa obteve ocorrência de $10,3 \%$ de respostas. Dentro do presídio está presente uma pastoral, que realiza atividades de leitura de textos religiosos e missa aos domingos. É possível que as pessoas que responderam a esse item sejam participantes das atividades dessa pastoral. As pessoas que responderam acho que não diminuiria com nada (7\%) provavelmente são aquelas que já assumiram o comportamento autolesivo de forma a não dar mais tanta importância à diminuição de sua ocorrência, possivelmente representando aquelas que já se feriram mais de 12 vezes.

\section{CONCLUSÃO}

Entre os vários motivos relacionados à autolesão foram identificados: alívio de sofrimento psíquico advindo da restrição da liberdade e do encarceramento; raiva de si ou de outro; uso de drogas (de forma correlacional, não causal); tentativa de manipular situações ou pessoas para obter vantagens; tentativa de chamar a atenção para si (individualidade, em oposição à coletividade); e imitação do comportamento autolesivo, quando observado que havia vantagens nele. A noção de autolesão com caráter manipulador recebeu pouca sustentação de outros investigadores a partir da crítica de que este tipo de ato é quase sempre impulsivo (Albanese, 1983); no entanto nossos dados mostram um caráter planejado desse tipo de comportamento, incluindo até mesmo rituais específicos quanto à conduta autolesiva das detentas. Dessa forma, apesar de poder haver casos específicos de condutas autolesivas patológicas na Colônia Penal Feminina, eles não constituem a maioria de nossa amostra, não se confirmando, assim, a afirmação de que a autolesão seria sempre um ato impulsivo. A instituição prisional se faz marcadamente presente nas condutas das pessoas presas, dessa vez por meio de um comportamento de aceitação social da autolesão no ambiente do presídio e, quem sabe, da organização de comportamentos que dizem respeito a uma identificação com esse ambiente particular.

Diante do exposto, sugerimos estratégias de intervenção que podem contribuir para a diminuição do número de ocorrências desse tipo de comportamento no presídio. Uma das coisas que se pretende fazer é marcar uma reunião com a psicóloga da Colônia Penal Feminina do Recife, para mostrar os resultados da pesquisa e discutir como o atendimento psicológico na instituição pode se tornar um instrumento de ajuda para combater o fenômeno da autolesão entre as detentas. Essa reunião incluiria em sua pauta a discussão sobre um possível curso de capacitação sobre autolesão, sem ônus, para os funcionários da penitenciária. Com a devida autorização da direção da Colônia Penal Feminina, esse curso teria como foco principal o comportamento autolesivo apresentado especificamente naquela unidade prisional. Avaliamos ainda que seria positiva a continuação do trabalho feito por ONGs ou outras entidades, pois esse tipo de atividade também proporciona um espaço de expressão livre de julgamentos para as detentas, num ambiente acolhedor. Dessa forma, tenta-se amenizar os efeitos negativos causados pelas condições hostis vividas num contexto de cárcere. Não obstante, existem fatores de difícil controle, como o contato das apenadas com suas famílias e a saída definitiva (não aquela proporcionada pelo regime semiaberto) da prisão.

\section{REFERÊNCIAS}

Assis, S.G. \& Constantino, P. (2001). Filhas do mundo: infração juvenil feminina no Rio de Janeiro. Rio de Janeiro: Fiocruz.

Flemming, J., McDonald, D. \& Biles, D. (1992). Self-inflicted harm in custody: Research paper n.16. In: Biles, D.; McDonald, D. (Org.), Deaths in custody in Australia 1980-1989: The research papers of the Criminology Unit of the Royal Commission into Aboriginal Deaths in Custody (381-416). Canberra: Australian Institute of Criminology.

Fotiadou, M., Livaditis, M., Manou, I., Kaniotou, E. \& Xenitidis, K. (2006). Prevalence of mental disorders and deliberate self-harm in Greek male prisoners. International Journal of Law and Psychiatry. 29(1), 68-73. Recuperado em 26 de junho de 2007 em http://www.ncbi.nlm.nih.gov/sites/entrez?cmd=Retrieve $\& d b=P u b$ Med\&list_uids=16266748\&dopt=Citation

Gabbard, G. (1992). Psiquiatria psicodinâmica na prática clínica. Porto Alegre: Artmed.

Hales, H., Davison, S., Misch, P. \& Taylor, P. J. (2003). Young male prisoners in a Young Offenders' Institution: their contact with suicidal behaviour by others. Journal of adolescence, 26(6), 66785. Recuperado em 01 agosto de 2008 em http://www.ncbi.nlm.nih.gov/pubmed/14643739 
Kaplan, H. I., Sadock, B. J. \& Grebb, J. A. (1997). Compêndio de psiquiatria - Ciências do comportamento e psiquiatria clínica. Porto Alegre: Artmed.

Klonsky, D. E., Oltmanns, T. F. \& Turkheimer, E. (2003). Deliberate self-harm in a nonclinical population: prevalence and psychological correlates. American Journal of Psychiatry, 160(8), 1501-1508. Recuperado em 25 setembro de 2005 em http://ajp.psychiatryonline.org/cgi/reprint/160/8/1501.pdf

Lemgruber, J. (1999). Cemitério dos vivos: Análise sociológica de uma prisão de mulheres. 2.ed., Rio de Janeiro: Forense.

O'Brien, M., Mortimer, L., Singleton, N. \& Meltzer, H. (2001) Psychiatric Morbidity among Women Prisoners in England and Wales. London: Office for National Statistics.

Pierce, D. (1984). Suicidal intent and repeated self-harm. Psychological Medicine, 14(3), 655-659.

Richardson, J. S. \& Zalesky, W. A. (1986). Endogenous opiates and self-mutilation. American Journal of Psychiatry, 143(7), 938-939. Recuperado em 20 setembro de 2005 em http://ajp.psychiatryonline.org/cgi/reprint/143/7/938b

Rocha, S. S. (2006) Falando sem palavras: o sintoma atravessado no corpo. São Leopoldo: Unisinos. Estados Gerais da psicanálise Grupos virtuais e textos. Recuperado em 06 de julho de $2007 \mathrm{em}$ http://www.estadosgerais.org/gruposvirtuais/rocha_sabrinafalando.shtml
Roth, B. \& Pressé, L. (2003). Nursing interventions for parasuicidal behaviors in female offenders. Journal of psychosocial nursing and mental health services, 41 (9):20-9. Recuperado em 01 de $\begin{array}{llll}\text { fevereiro } & \text { de } & 2008 & \text { em }\end{array}$ http://www.ncbi.nlm.nih.gov/pubmed/14502811

Safer Custody Group (2006). Reported self-harm in prisons in 2006. Unpublished Report. Londres: HM Prison Service.

Suyemoto, K. L. (1998). The functions of self-mutilation. Clinical Psychology Review, 18(5), 531-554.

Severino, A. J. (2007). Metodologia do Trabalho Científico. São Paulo: Cortez.

Yaryura-Tobias, J. A., Mancebo, M. C. \& Neziroglu, F.A. (1999). Questões teórico-clínicas do comportamento de automutilação. Revista Brasileira de Psiquiatria, 21(3), 178-183. Recuperado em 17 de agosto de 2005 em http://www.scielo.br/scielo.php?script=sci_arttext\&pid=S151644461999000300011

Endereço para correspondência : Marcus Túlio Caldas. Rua Dr. Vicente Meira, 82, ap. 1601, Graças, CEP: 52020-130, RecifePE, Brasil E-mail: marcus_tulio@uol.com.br 